\title{
Novel Variants in COL4A3 and COL4A4 are Causes of Alport Syndrome in Rio
}

\section{Grande do Norte, Brazil}

Washington Candeia de Araújo ${ }^{1,2^{*}}$, Raul Maia Falcão ${ }^{3^{*}}$, Raquel Uchoa ${ }^{1}$, Carlos Alexandre Garcia $^{1}$, Jorge Estefano S. de Souza ${ }^{3}$ and Selma M. B. Jeronimo ${ }^{1,2,4}$.

${ }^{1}$ Institute of Tropical Medicine of Rio Grande do Norte, Federal University of Rio Grande do Norte, Natal, RN, Brazil.

${ }^{2}$ Department of Biochemistry, Biosciences Center, Federal University of Rio Grande do Norte, Natal, RN, Brazil.

${ }^{3}$ Biome, Bioinformatics Multidisciplinary Environment, Federal University of Rio Grande do Norte, Natal, RN, Brazil.

${ }^{4}$ National Institute of Science and Technology of Tropical Diseases, Natal, Rio Grande do Norte, Brazil.

*These authors contributed equally to this work. 


\begin{abstract}
Background. Alport syndrome is a progressive and hereditary nephropathy, characterized by hematuria and proteinuria, and extrarenal manifestations as hearing loss and eye abnormalities. The disease can be expressed as autosomal recessive or dominant, caused by variants in COL4A3 and COL4A4 loci, respectively, or X-linked caused by variants in COL4A5 locus.
\end{abstract}

Methods. Two unrelated families with Alport Syndrome from northeast of Brazil were studied and whole exome sequencing were performed. DNA sequences were mapped against the human genome (GRCh38/hg38 build) to identify associated mutations.

Results. Variant analysis showed deleterious variants in COL4A3 and COL4A4 loci in chromosome 2. Two variants were detected with alternative alleles in a homozygous state in the probands. One novel premature stop codon at position 481 of COL4A3 protein is present in one family and one frameshift mutation leading to a premature stop codon at position 786 of COL4A4 protein in the other family. Both Alport cases presented their variants surrounded by a broad runs of homozygosity $(\mathrm{ROH})$.

Conclusions. The autosome recessive inheritance coupled with the runs of homozygosity in both families suggest inbreeding.

Keywords: Alport Syndrome, whole exome sequencing, runs of homozygosity, kidney diseases, collagen type IV 


\section{Introduction}

Alport syndrome is a hereditary Mendelian disease in which individuals progress with hematuric nephritis and sensorineural deafness. These symptoms are the results of defect in the glomerular basement membranes biogenesis [1]. The pathophysiology of Alport Syndrome consists of structural defects in type IV collagen alpha chains that constitutes the glomerular basement membrane [2-3]. Collagen type IV are encoded by six distinct genes (COL4A1 to COL4A6) consisting of six alpha chains ( $\alpha 1-\alpha 6)$ which assemble in heterotrimers (three $\alpha$ chains coiled together) forming a protomer [4-5]. There are three major mutations in $\alpha 3$, $\alpha 4$ or $\alpha 5$ generating defective type IV collagen networks and preventing proper structure of glomerular basement membrane [6-7].

Although there are six alpha chains, only three different protomers are known, a1a1a2 (IV), a5a5a6 (IV) and a3a4a5 (IV) [8-10]. Those protomers form the type IV collagen networks which are an essential part of the extracellular matrix and the structure of all basement membrane. Type IV protomers consists in a triple collagenous helix domain of about $400 \mathrm{~nm}$, characterized by a triplet amino acid repeat sequence of Gly-XY. Furthermore, a globular non-collagenous domain is found in the 3' as well as a short domain, called 7S in the 5' end. These domains form a dense collagens IV network, once secreted in the extracellular matrix [11-12].

The a1a1a2 (IV) protomer is ubiquitously distributed in all basement membranes during embryogenesis, later are replacing by the protomer a3a4a5 (IV) in glomerular basement membrane and protomer $a 5 a 5 a 6$ in other tissues [13]. The $a 3 \alpha 4 a 5$ (IV) is known to be more cross-linked protomer [14-15], resulting in a stronger and more resistant heterotrimer [16] Collagen IV network has a crucial role for development of glomerular basement membrane during ontogenesis, which helps to support tissue 
integrity besides cell signaling, morphogenesis and tissue regeneration [4]. There is an interaction in the biogenesis of collagen produced by podocytes and the glomerular basement membrane. Moreover, a3a4a5 (IV) protomer is also produced in other tissues, such as the cochlea and eyes [17-18].

There are several variants described for the COL4A3 (I120070, OMIM) loci and COL4A4 (120131, OMIM) loci, localized in 2q35-37, and COL4A5 (303630, OMIM) locus. Autosomal recessive Alport Syndrome is related to modifications in the $\alpha 3$ (IV) and $\alpha 4$ (IV) chains, whereas X-linked Alport Syndrome is related to modifications in the a5 (IV). In the case of $a 6$ chain, although the $\alpha 5 a 5 a 6$ (IV) protomers can be formed in autosomal recessive Alport Syndrome. Experimental study demonstrated that this gene is not associated with Alport Syndrome [19]. Both modifications affect the biogenesis of type IV collagen and lead to a reduction or absence of these molecules in glomerular basement membrane progressing to a renal failure [20].

Inbreeding can increase the risk of Alport syndrome [21]. Recent studies have showm an increase of genomic homozygosity with increasing consanguinity [22-26]. In this work, we report the results of Alport syndrome cases from two families from the Northeast region of Brazil. We identify two novel variants (stop codon gained and frameshift) and the mutations result in a truncated $\alpha 3$ and $\alpha 4$ chains. In addition, there is a broad region of runs of homozygosity $(\mathrm{ROH})$. 


\section{Material and Methods}

\section{Biological material from patients (Families Sampling)}

Two unrelated families, Family 1 (F1) and Family 2 (F2), of the Northeast region in Brazil (Rio Grande do Norte state) were evaluated. Nuclear Family 1 had 4 cases of Alport, but within the extended family there were 5 other cases, all had been transplanted and Family 2 apparently had a sporadic case of Alport.

\section{Ethical Considerations}

The study protocol was reviewed and approved by the Federal University Ethical Committee (CEP-UFRN 50-01) and by the Brazilian Ethical Committee (CONEP-4569). All participants and-or legal guardians read, approved and signed the informed consent. Subjects with medical conditions discovered during the study were treated by the study team or referred or taken to the appropriate medical resource in Natal. Subjects with Alport syndrome had already been transplanted at the time of recruitment and they were been followed at the University Hospital for their medical care.

\section{DNA extraction}

DNA was extracted from $10 \mathrm{ml}$ of anticoagulated whole blood (EDTA) by erythrocyte lysis in $70 \mu \mathrm{g}$ of $\mathrm{NH}_{4} \mathrm{H}_{2} \mathrm{CO}_{3} / \mathrm{ml}$ and $7.0 \mathrm{mg}$ of $\mathrm{NH}_{4} \mathrm{Cl} / \mathrm{ml}$ followed by lysis of leukocytes in $1 \%$ sodium dodecyl sulfate, $100 \mathrm{mM}$ EDTA, and $200 \mathrm{mM}$ Tris (pH 8.5) and precipitation in isopropanol. DNA sample underwent quality control which included gel electrophoresis and quantification and determination of integrity by fluorometer (qubit, Themo Fisher, USA).

\section{Whole Exome Sequencing}


In each family the father, mother, unaffected sibling and proband $(n=4)$ had their exomes sequenced. Whole exome sequencing (WES) was performed by the University of lowa Genomics Division using manufacturer recommended protocols. Briefly, $3 \mu \mathrm{g}$ of genomic DNA were sheared using the Covaris E220 sonicator. The sheared DNA was used to prepare indexed whole exome sequencing libraries using the Agilent SureSelect XT Human all exon v6 + UTR kit (Agilent Technologies, Santa Clara, CA, Cat. No. 51908883). The molar concentrations of the indexed libraries were measured using the Fragment Analyzer (Agilent Technologies) and combined equally into pools for sequencing. The pooled libraries were loaded on an Illumina HiSeq 4000 genome sequencer using the $2 \times 150 \mathrm{bp}$ paired-end sequencing by synthesis (SBS) chemistry.

\section{Raw Reads Preprocessing and Reference Genome Mapping}

FastQC (v0.11.4) [27] software was used to quantify the sequences and to analyze the sequencing quality. Adapters was removed by Trim Galore (v0.4.1) [28] using the option to execute Cutadapt (v1.8.3) [29], with default values. Reads were mapped using BWA (v0.7.12-r1039) [30] software, with mem mode against to GRCh38/hg38 build [31]. Functions stats and depth from SAMtools (v1.7) [32] were used to calculate total reads mapped, total exome mean coverage and mean coverage in $\mathrm{ROH}$ and remaining regions. Normalized mean coverage was calculated dividing the average coverage per base by the individual number of reads sequenced then multiplying by the average of reads sequenced of all individuals. Also, mpileup function from SAMtools was used to generate input to VarScan2 (v2.3.9) [33] software.

\section{Runs of Homozygosity (ROH) ratio}

To obtain total chromosomal ROH lengths the algorithm H3M2 [34] was used followed by a filter of long $\mathrm{ROH}$ fragments lengths $(1.5 \mathrm{Mb})$. The software was applied in 
the mapping file for each individual sample of this study. A reference length of $\mathrm{ROH}$ was determined by applying H3M2 with the same filter in 20 random publicly available CEU samples sequenced by the 1000 Genomes Project [35]. Thus, as a measure of the consanguinity/endogamy a homozygous ratio was calculated dividing the total $\mathrm{ROH}$ length of each family member by the average of $\mathrm{ROH}$ length from $\mathrm{CEU}$ samples.

\section{Variant Calling and Data Refinement}

Best practices from Genome Analysis ToolKit (v3.4-46) HaplotypeCaller [36] (GATK-HC) were performed with Base Quality Score Recalibration (BQSR) mode using the following known sites: The Single Nucleotide Polymorphism Database (dbSNP 146); Mills \& $1000 \mathrm{G}$ gold standard indels for hg38 and 1000G phase1 SNPS high confidence sites for hg38. Vcftools (v0.1.13) [37] was used to filter low coverage variants and to maintain records with at least one sample with variant call data. Variants with minDP < 20 and max-missing $>0.125$ were eliminated from the analysis. Vcfstats [38] from vcflib package was used to summarize basic variant calling statistic.

\section{Homozygosity Mapping, Variant Annotation and Haplotype Phasing}

To detect differences between the homozygous and heterozygous signals Homozygous Stretch Identifier - HomSI (v2.1) [39] - software was used with default parameters values. Databases such as Exome Aggregation Consortium [40], 1000 Genomes Project and dbSNP 146 were integrated and variants were annotated by ANNOVAR (v2018Apr16) [41] and SnpEff (v 4.1) [42] software, respectively. Missing data inference and haplotype phasing were performed using Beagle (v5.1) [43] software.

\section{Identification of deleterious variants}


The analysis focused on identifying homozygous pathogenic variants. We restricted the exome sequence data to variants with 1 ) allelic frequencies $<1 \%$ in Exome Aggregation Consortium database; 2) gene and protein expression (> 1 FPKM) in kidney, cochlea and eye from Illumina Body Map, The Human Protein Atlas (HPA) and GenotypeTissue Expression Project database; 3) clinical significance from ClinVar database. Variants with a structural effect (frameshift and stop codon gained) were considered deleterious. 


\section{Results}

\section{Genotyping and exome Screening}

On average $98.6 \%$ of the exome-wide was covered with at least 20 -fold coverage at $\sim 190 x$ of coverage (Supplementary Table S1). A total of $106,726(97,327$ SNVs, 9 MNPs and 9,390 INDELS) variants were reported and Ti/Tv ratio was equal to 2.4. From those, 16,830 variants were nonsynonymous, 124 stop codons gained and 262 were frameshifts.

A total of 12 deleterious variants were identified ( 1 stop codon gained and 11 frameshift) with alternative allele homozygous state exclusively in probands (Supplementary Table S2). From these 12 variants, 8 variants had an allele frequency greater than $1 \%$ in the Exome Aggregation Consortium database including one variant classified as benign clinical significance in the clinvar database; 2 variants were not expressed in any of the organs involved in Alport disease. Two of the 12 variants were classified as possibly pathogenic and present in genes expressed in the kidney, eye and cochlea. The two later variants are directly linked to collagen type IV production and present in COL4A3 (p.Try481*) and COL4A4 (p.Val741fs) loci. No deleterious variants were found in COL4A5.

\section{Variants along COL4A genes}

Twenty-three variants (Supplementary Table S3) were present in COL4A genes. Twelve variants were presents in COL4A4 (6 synonymous, 5 non-synonymous and 1 frameshift) and eleven in COL4A3 (3 synonymous, 7 non-synonymous and 1 stop gain). Figure 1 shows the distribution of all nonsynonymous and deleterious variants in this study in COL4A4, COL4A3 and COL4A5 loci. Only stop gained and frameshift variants 
were not reported in the ClinVar database. All other variants were reported on Clinvar as benign for cases of Alport Syndrome.

Eleven variants in COL4A3 occurred at triple helix region domain of collagen type IV. We observed a premature stop codon gained (p.Try481*) in all members among Family 1. In this family, proband presented this variant with alternative allele in homozygous state. Other individuals of this family had the same variant at heterozygous state. All members of Family 1, except the proband, have the same genotype in this locus, whereas members of Family 2 do not have this variant.

Nine variants in COL4A4 occurred at triple helix region domain of collagen type IV. We observed a frameshift (p.Val741fs) in all members among Family 2. In this family, proband had a homozygous frameshift leading to a truncated protein with 786 amino acids. Other members of this family had the same frameshift at heterozygous state. Members of Family 1 do not have this variant.

\section{Segregation analysis in COL4A genes}

Haplotype phasing showed offspring's alleles were inherited together from copies of paternal and maternal chromosomes. Both probands presented an excess of nonsynonymous variants at homozygous state. For Family 1, proband had four variants in COL4A3 and all remain members had the same three variants in COL4A3. Conversely, Family 2 proband had four variants in COL4A3 and three in COL4A4 loci while all remain members had at most three variants distributed in both COL4A genes. All variants of the genes encoding $\alpha 4$ and $\alpha 3$ chains of collagen type IV perfectly co-segregated with the disease in both families (Figure 2). All individuals showed approximately 190x (Table 1) of coverage in homozygous regions and remaining regions. 
Non-synonymous variant alleles found in COL4A genes, when analyzed individually, occurred at high allelic frequency rates in the 1KGP database. However, their co-occurrence with haplotype frequency was rare in all cases. Co-occurrence including deleterious variants presented in this study did not occur in any $1 \mathrm{KGP}$ individual.

\section{Homozygous regions in COL4A genes}

Chromosome 2 showed a common $\mathrm{ROH}$ locus in both probands (Figure 3). In Family 1 proband has a homozygous locus of $20 \mathrm{Mb}$ with 140 genes. In Family 2 proband has a homozygous locus of $75 \mathrm{Mb}$ with 364 genes. By analyzing this region, we observed that only the COL4A3 and COL4A4 genes had deleterious variants.

An average of $116,876,596$ bp of $\mathrm{ROH}$ length for CEU population (Supplementary Table S4). The total of $\mathrm{ROH}$ fragments, $\mathrm{ROH}$ length for all autosomal chromosomes and homozygous ratio for each member of the family (Table 2 and 3 ) showed high level of consanguinity, with high homozygous ratio in the offspring. Family 1 had a homozygous ratio of $1.05,2.15,3.53$ and 2.03 for the father, the mother, the unaffected son and the proband respectively. Family 2 had a homozygous ratio of $0.70,0.56,3.15$ and 2.09 for father, mother, unaffected son and proband respectively. This result highlighted a relation with the number of long fragments of $\mathrm{ROH}$ and homozygous ratio: the higher values of fragments, the higher values of homozygous ratio. 


\section{Discussion}

In the present study, we investigated two families from northeast of Brazil with Alport Syndrome and we report two novel variants responsible for the disease. The first one was a novel nonsense mutation in COL4A3 gene in proband from Family 1. The second one was a frameshift in COL4A4 locus in proband from Family 2. Both findings occurred in triple helix domain and had a broad region of $\mathrm{ROH}$ covering both genes in probands. Cosgrove and Liu [8] states that stop codon gained, frameshifts and other mutations that result in chain termination are associated with a more severe phenotype.

Szpiech et al [44] using data obtained by whole exome sequencing demonstrated that a significantly larger fraction of all predicted harmful homozygous variants are surrounded by $\mathrm{ROH}$ stretch when compared to those corresponding fractions of nondamaging homozygous variants. Long $\mathrm{ROH}(>1.5 \mathrm{Mb})$ are known to be favored by inbreeding and IBD inheritance processes and characterized by an enrichment of deleterious recessive mutations $[45,46]$. Most recessive disease variants are identified via homozygosity mapping. Using high-density genome-scan data in European populations McQuillan et al [24] indicate that the numbers and lengths for ROHs above $1.5 \mathrm{Mb}$ are clearly relation to endogamy and isolation behind the effects on $\mathrm{ROHs}$, as occurred in our Alport syndrome.

A homozygous region was present in both probands in chromosome two but being broader in Family 2 when compared to Family 1 (Figure 2). Although unaffected offspring had the highest value for homozygous ratio (Table 2 and Table 3), in both families, type IV collagen is not affected. A possible explanation for this excessive homozygosity in the loci region of COL4A3 and COL4A4, would be a large deletion occurring in the probands leading to uniparental inheritance. However, the phasing of chromosomes as well as the 
average of coverage in $\mathrm{ROH}$ and remaining regions (Figure 2 and Table 1) pointed out to an allele inheritance and not to a deletion inheritance rejecting a hypothesis of deletion event. Recent studies $[47,48]$ reported that mutations in COL4A3 and COL4A4 loci, when in cis, can lead to a form of benign familial hematuria, in a similar genetic way as Alport syndrome. Benign familial hematuria is considered as a phenotypic expression and represents a carrier state for autosomal recessive Alport syndrome.

All family 1 members have a nonsense variant (p.Tyr481*) in COL4A3 gene, although only the proband has it with alternative allele at homozygous state. This variant is novel. In addition, it is known that COL4A3 nonsense phenotype is severe and associated with end-stage renal disease, deafness and ocular lesions [11]. As reported in this study, the observed stop codon gained falls in collagenous domain of type IV collagen leading to a truncated protein, and consequently destabilizing collagen IV network formation. Other mutations may increase the risk of AS because they had perfectly co-segregated with disease. In this family we observed all members having high homozygosity rate.

Members of family 2 had a frameshift variant (p.Val741fs) in COL4A4 gene, but only the proband has with alternative allele at homozygous recessive state (see Table 1). Frameshift is the most important evidence for Alport Syndrome heritage in this family due to the insertion of one base in the reading frame and led to a truncated protein with 786 residues. Thus, herein we propose Alport Syndrome resulting in phenotype of proband in this family. Zhu et al [49] obtained a similar result using next generation sequencing and identified a frameshift leading to truncated COL4A4 protein with 1634 amino acids and considering as a loss of function variant. In this family we noticed only the offspring had 
high homozygosity rate. This reflects origin from a small isolated population and presents features such as population genetic historical and geographical factors.

\section{Conclusions}

This work describes two novel variants responsible for Alport cases in two families from northeast of Brazil. Those variants were searched in the databases of 1000 genomes and Clinvar and they are rare alleles, not yet identified in the world population. The two pathogenic variants identified are located on an $\mathrm{ROH}$ locus. Interestingly both Alport probands have $\mathrm{ROH}$ in the COL4A3 and COL4A4 loci, and all variants are homozygous. There is a need to screen people who have lost kidney function for genetic mutations, allowing a better understanding of Alport Syndrome and their respective penetrance. In addition, it is important to identify people heterozygous for variants associated with Alport Syndrome in areas with high level of inbreeding. 


\section{Acknowledgement}

The authors thank Jose Wellington for his help in recruitment of the Alport families and the staff from the Hospital Universitario Onofre Lopes. The authors also thank the Alport families for participating in this study. WCA received a fellowship from CAPES/FAPERN and RMD to CAPES and Rede de Pesquisa em Genômica Populacional Humana (RedePGH) supported by Universidade Federal do Pará (UFPA). All analysis was performed at Supercomputer of UFRN (23001011020P6 Project). 


\section{References}

1. Funk SD, Lin MH, Miner JH. Alport syndrome and Pierson syndrome: Diseases of the glomerular basement membrane. Matrix Biol 2018;71-72:250-61. doi:10.1016/j.matbio.2018.04.008

2. Rinschen MM, Benzing T, Limbutara K, et al. Proteomic analysis of the kidney filtration barrier-Problems and perspectives. Proteomics - Clin Appl 2015;9:105368. doi:10.1002/prca.201400201

3. Stokman MF, Renkema KY, Giles RH, et al. The expanding phenotypic spectra of kidney diseases: Insights from genetic studies. Nat Rev Nephrol 2016;12:472-83. doi:10.1038/nrneph.2016.87

4. Pedchenko V, Kitching AR, Hudson BG. Goodpasture's autoimmune disease - A collagen IV disorder. Matrix Biol 2018;71-72:240-9. doi:10.1016/j.matbio.2018.05.004

5. Fidler AL, Darris CE, Chetyrkin S V., et al. Collagen iv and basement membrane at the evolutionary dawn of metazoan tissues. Elife 2017;6:1-24. doi:10.7554/eLife.24176.001

6. Nozu K, Nakanishi K, Abe Y, et al. A review of clinical characteristics and genetic backgrounds in Alport syndrome. Clin Exp Nephrol 2019;23:158-68. doi:10.1007/s10157-018-1629-4

7. Iozzo R V., Gubbiotti MA. Extracellular matrix: The driving force of mammalian diseases. Matrix Biol 2018;71-72:1-9. doi:10.1016/j.matbio.2018.03.023

8. Cosgrove D, Liu S. Collagen IV diseases: A focus on the glomerular basement membrane in Alport syndrome. Matrix Biol 2017;57-58:45-54. doi:10.1016/j.matbio.2016.08.005 
9. Kruegel J, Rubel D, Gross O. Alport syndrome - Insights from basic and clinical research. Nat Rev Nephrol 2013;9:170-8. doi:10.1038/nrneph.2012.259

10. Borza DB, Bondar O, Ninomiya Y, et al. The NC1 Domain of Collagen IV Encodes a Novel Network Composed of the $\alpha 1, \alpha 2$, $\alpha 5$, and $\alpha 6$ Chains in Smooth Muscle Basement Membranes. J Biol Chem 2001;276:28532-40. doi:10.1074/jbc.M103690200

11. Gubler MC. Inherited diseases of the glomerular basement membrane. Nat Clin Pract Nephrol 2008;4:24-37. doi:10.1038/ncpneph0671

12. Than ME, Henrich $S$, Huber $R$, et al. The 1.9- $\AA$ crystal structure of the noncollagenous (NC1) domain of human placenta collagen IV shows stabilization via a novel type of covalent Met-Lys cross-link. Proc Natl Acad Sci U S A 2002;99:6607-12. doi:10.1073/pnas.062183499

13. Ninomiya $\mathrm{Y}$, Kagawa M, lyama KI, et al. Differential expression of two basement membrane collagen genes, COL4A6 and COL4A5, demonstrated by immunofluorescence staining using peptide-specific monoclonal antibodies. J Cell Biol 1995;130:1219-29. doi:10.1083/jcb.130.5.1219

14. Gunwar, S., Ballester, F., Noelken, M. E, et al. (1998). Glomerular basement membrane. Identification of a novel disulfide- cross- linked network of $\alpha 3, \alpha 4$, and a5 chains of type IV collagen and its implications for the pathogenesis of Alport syndrome. Journal of Biological Chemistry, 273(15), 8767-8775. https://doi.org/10.1074/jbc.273.15.8767

15. Kalluri R, Shield CF, Todd $\mathrm{P}$, et al. Isoform switching of type IV collagen is developmentally arrested in X- linked Aport syndrome leading to increased susceptibility of renal basement membranes to endoproteolysis. J Clin Invest 1997;99:2470-8. doi:10.1172/JCl119431 
16. Bai X, Dilworth DJ, Weng YC, et al. Developmental distribution of collagen IV isoforms and relevance to ocular diseases. Matrix Biol 2009;28:194-201. doi:10.1016/j.matbio.2009.02.004

17. lozzo R V., Gubbiotti MA. Extracellular matrix: The driving force of mammalian diseases. Matrix Biol 2018;71-72:1-9. doi:10.1016/j.matbio.2018.03.023

18. Hasegawa $\mathrm{H}$, Naito I, Nakano K, et al. The distributions of type IV collagen a chains in basement membranes of human epidermis and skin appendages. Arch. Histol. Cytol. 2007;70:255-65. doi:10.1679/aohc.70.255

19. Murata T, Katayama K, Oohashi T, et al. COL4A6 is dispensable for autosomal recessive Alport syndrome. Sci Rep 2016;6:1-11. doi:10.1038/srep29450

20. Boutaud A, Borza DB, Bondar O, et al. Type IV collagen of the glomerular basement membrane. Evidence that the chain specificity of network assembly is encoded by the noncollagenous NC1 domains. J Biol Chem 2000;275:30716-24. doi:10.1074/jbc.M004569200

21. Yang C, Song Y, Chen Z, et al. A Nonsense Mutation in COL4A4 Gene Causing Isolated Hematuria in Either Heterozygous or Homozygous State. Front Genet 2019;10:1-8. doi:10.3389/fgene.2019.00628

22. Bittles $\mathrm{AH}$, Black ML. Consanguinity, human evolution, and complex diseases. Proc Natl Acad Sci U S A 2010;107:1779-86. doi:10.1073/pnas.0906079106

23. Carothers A. D., Rudan I., Kolcic I., et al. Estimating human inbreeding coefficients: Comparison of genealogical and marker heterozygosity approaches. Annals of Human Genetics 2006, 70(5), 666-676. https://doi.org/10.1111/j.14691809.2006.00263.x 
24. McQuillan R, Leutenegger AL, Abdel-Rahman R, et al. Runs of Homozygosity in European Populations. Am J Hum Genet 2008;83:359-72. doi:10.1016/j.ajhg.2008.08.007

25. Kirin M, McQuillan R, Franklin CS, et al. Genomic runs of homozygosity record population history and consanguinity. PLoS One 2010;5:1-7. doi:10.1371/journal.pone.0013996

26. Nothnagel M, Lu TT, Kayser M, et al. Genomic and geographic distribution of snpdefined runs of homozygosity in Europeans. Hum Mol Genet 2010;19:292735. doi:10.1093/hmg/ddq198

27. Andrews S. (2010). FastQC: a quality control tool for high throughput sequence data. Available online at: http://www.bioinformatics.babraham.ac.uk/projects/fastqc.

28. Krueger F. A wrapper tool around Cutadapt and FastQC to consistently apply quality and adapter trimming to FastQ files, with some extra functionality for Mspldigested RRBS-type (Reduced Representation Bisufite-Seq) libraries. Available online at: http://www.bioinformatics.babraham.ac.uk/projects/trim_galore/.

29. Martin M. Cutadapt removes adapter sequences from high-throughput sequencing reads. EMBnet.journal 2011;17:10-2. doi:10.14806/ej.17.1.200

30. Li H. Aligning sequence reads, clone sequences and assembly contigs with BWAMEM. 2013;00:1-3.http://arxiv.org/abs/1303.3997

31. Rosenbloom KR, Armstrong J, Barber GP, et al. The UCSC Genome Browser database: 2015 update. Nucleic Acids Res 2015;43:D670-81. doi:10.1093/nar/gku1177

32. Li H, Handsaker B, Wysoker A, et al. The Sequence Alignment/Map format and SAMtools. Bioinformatics 2009;25:2078-9. doi:10.1093/bioinformatics/btp352 
33. Koboldt DC, Zhang Q, Larson DE, et al. VarScan 2: Somatic mutation and copy number alteration discovery in cancer by exome sequencing. Genome Res 2012;22:568-76. doi:10.1101/gr.129684.111

34. Magi A, Tattini L, Palombo F, et al. H3M2: detection of runs of homozygosity from whole-exome sequencing data. Bioinformatics 2014;30:2852-9. doi:10.1093/bioinformatics/btu401

35. Auton A, Abecasis GR, Altshuler DM, et al. A global reference for human genetic variation. Nature 2015;526:68-74. doi:10.1038/nature15393

36. Van der Auwera GA, Carneiro MO, Hartl C, et al. From FastQ data to high confidence variant calls: the Genome Analysis Toolkit best practices pipeline. Curr Protoc Bioinforma Ed Board Andreas Baxevanis Al 2013;43:11.10.1-33. doi:10.1002/0471250953.bi1110s43

37. Danecek P, Auton A, Abecasis G, et al. The variant call format and VCFtools. Bioinformatics 2011;27:2156-8. doi:10.1093/bioinformatics/btr330

38. Garrison E, Yandell M, Shapiro M, et al. VCFLIB : an ensemble of methods for variant manipulation and population genetics.

39. Lek M. Analysis of protein-coding genetic variation in 60,706 humans. $2015 ;: 1-26$.

40. Görmez Z, Bakir-Gungor B, Sağiroğlu MŞ. HomSI: A homozygous stretch identifier from next-generation sequencing data. Bioinformatics 2014;30:445-7. doi:10.1093/bioinformatics/btt686

41. Wang K, Li M, Hakonarson H. ANNOVAR: Functional annotation of genetic variants from high-throughput sequencing data. Nucleic Acids Res 2010;38:1-7. doi:10.1093/nar/gkq603 
42. Cingolani P, Platts A, Wang LL, et al. A program for annotating and predicting the effects of single nucleotide polymorphisms, SnpEff. Fly (Austin) 2012;6:80-92. doi:10.4161/fly.19695

43. Browning SR, Browning BL. Rapid and accurate haplotype phasing and missingdata inference for whole-genome association studies by use of localized haplotype clustering. Am J Hum Genet 2007;81:1084-97. doi:10.1086/521987

44. Szpiech ZA, Xu J, Pemberton TJ, et al. Long runs of homozygosity are enriched for deleterious variation. Am J Hum Genet 2013;93:90-102. doi:10.1016/j.ajhg.2013.05.003

45. Pemberton TJ, Szpiech ZA. Relationship between Deleterious Variation, Genomic Autozygosity, and Disease Risk: Insights from The 1000 Genomes Project. Am J Hum Genet 2018;102:658-75. doi:10.1016/j.ajhg.2018.02.013

46. Sund KL, Rehder CW. Detection and reporting of homozygosity associated with consanguinity in the clinical laboratory. Hum Hered 2014;77:217-24. doi:10.1159/000362448

47. Mencarelli MA, Heidet L, Storey $\mathrm{H}$, et al. Evidence of digenic inheritance in alport syndrome. J Med Genet 2015;52:163-74. doi:10.1136/jmedgenet-2014-102822

48. Papazachariou L, Papagregoriou G, Hadjipanagi D, et al. Frequent COL4 mutations in familial microhematuria accompanied by later-onset Alport nephropathy due to focal segmental glomerulosclerosis. Clin Genet 2017;92:51727. doi:10.1111/cge.13077

49. Zhu F, Li W, Li Z, et al. Identification of a novel COL4A4 variant in compoundheterozygous state in a patient with Alport syndrome and histological findings similar to focal segmental glomerulosclerosis (FSGS). Front Genet 2019;10:1-6. doi:10.3389/fgene.2018.00748 
Figure 1. Distribution of deleterious and homozygous non-synonymous variants in COL4A4, COL4A3 and COL4A5 genes.

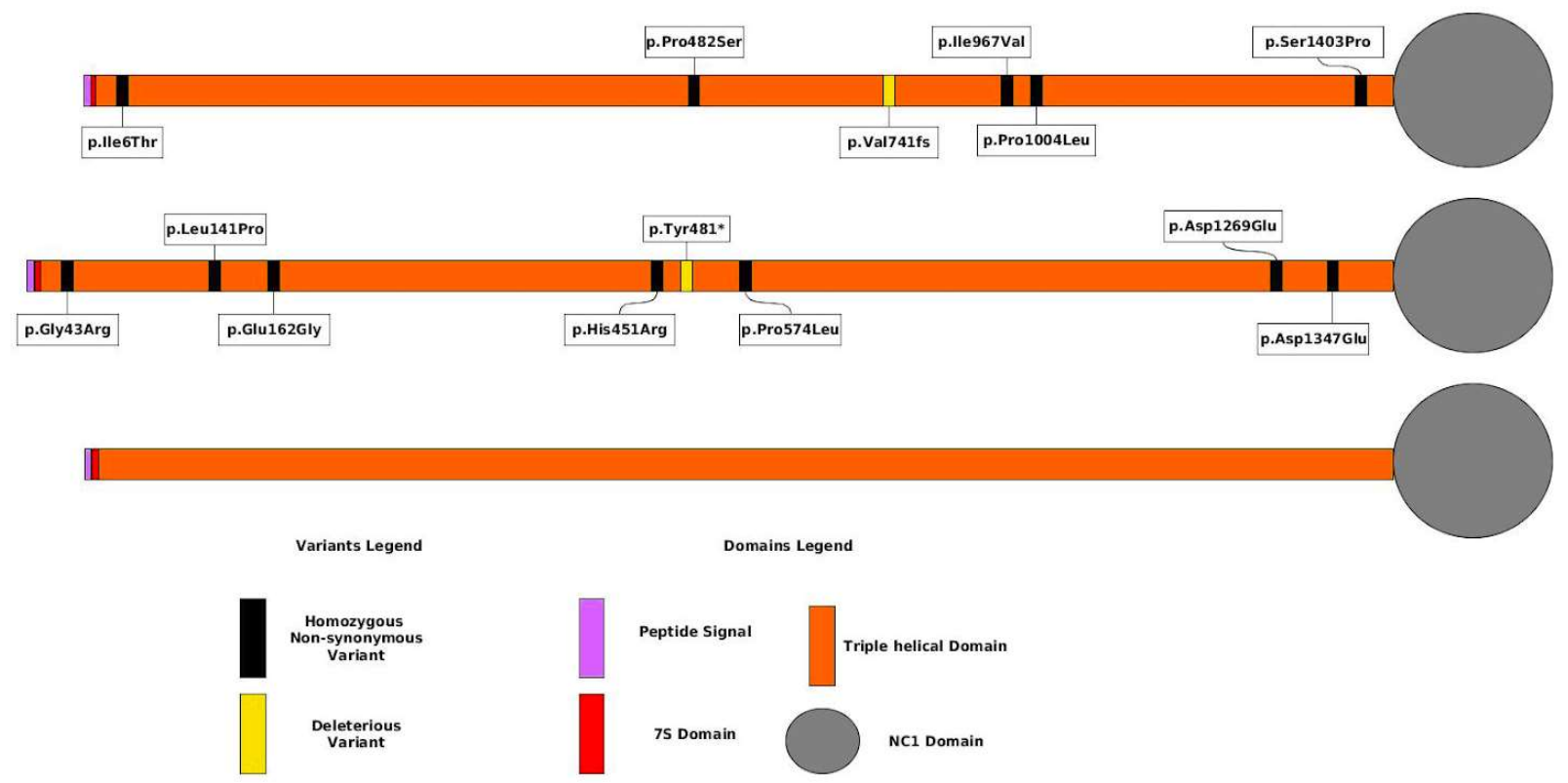

Supplementary Table S1: Exome-wide base coverage summary

\begin{tabular}{ccccc}
\hline Sample & $\begin{array}{c}\text { Total Mapped } \\
\text { reads }\end{array}$ & $\begin{array}{c}\text { Total exome } \\
\text { mean coverage } \\
\text { (normalized) }\end{array}$ & $\begin{array}{c}\text { Total Covered } \\
\text { Bases (20x fold) }\end{array}$ & $\begin{array}{c}\text { \% 20x fold bases } \\
\text { covered }\end{array}$ \\
\hline Father (F1) & $157,896,820$ & 194.15 & $89,152,408$ & 98.54 \\
\hline Mother (F1) & $180,487,311$ & 189.62 & $89,312,826$ & 98.71 \\
\hline Son (F1) & $204,975,749$ & 184.55 & $89,624,633$ & 99.06 \\
\hline Proband (F1) & $147,647,415$ & 191.20 & $88,816,063$ & 98.16 \\
\hline Father (F2) & $212,010,435$ & 191.23 & $89,699,378$ & 98.74 \\
\hline Mother (F2) & $187,140,367$ & 193.47 & $89,334,742$ & 98.37 \\
\hline Son (F2) & $185,054,786$ & 194.51 & $89,003,689$ & 98.36 \\
\hline Proband (F2) & $153,688,254$ & 195.54 & $88,989,473$ & \\
\hline
\end{tabular}




\begin{tabular}{|c|c|c|c|c|c|c|c|c|c|c|c|c|c|c|c|}
\hline \multicolumn{16}{|c|}{$\begin{array}{l}\text { Supplementary Table S2: Possibly delete } \\
\text { state in remains members of the family }\end{array}$} \\
\hline $\begin{array}{l}\text { Proband' } \\
\text { s Fam }\end{array}$ & Position & dbSNP_ID & Gene & $\begin{array}{l}\text { Variant } \\
\text { Effect }\end{array}$ & $\begin{array}{l}\text { Clin } \\
\text { Var }\end{array}$ & $\begin{array}{l}\text { ExAC } \\
\text { allele } \\
\text { frequency }\end{array}$ & $\begin{array}{c}\text { RNASeq } \\
\text { Kidney } \\
\text { expressio } \\
n^{*}\end{array}$ & $\begin{array}{c}\text { HPA } \\
\text { Kidney } \\
\text { Expressio } \\
n^{*}\end{array}$ & $\begin{array}{l}\text { GTEx Ki } \\
\text { dney } \\
\text { Expressi } \\
\text { on* }^{*}\end{array}$ & $\begin{array}{c}\text { RNASeq } \\
\text { Retina } \\
\text { Expressi } \\
\text { on* }^{*}\end{array}$ & $\begin{array}{c}\text { HPA } \\
\text { Retina } \\
\text { Expressi } \\
\text { on* }^{*}\end{array}$ & $\begin{array}{c}\text { GTEx R } \\
\text { etina } \\
\text { Expressi } \\
\text { on* }^{*}\end{array}$ & $\begin{array}{c}\text { RNASeq } \\
\text { Ear } \\
\text { Expressi } \\
\text { on* }^{*}\end{array}$ & $\begin{array}{l}\text { HPA Ear } \\
\text { Expressi } \\
\text { on }^{*}\end{array}$ & $\begin{array}{c}\text { GTEx E } \\
\text { ar } \\
\text { Expressi } \\
\text { on* }^{*}\end{array}$ \\
\hline 1 & $\begin{array}{c}\text { Chr2:1744 } \\
27852\end{array}$ & $\begin{array}{c}\text { rs } 1456990 \\
77\end{array}$ & SCRN3 & $\begin{array}{l}\text { FRAME } \\
\text { SHIFT }\end{array}$ & NA & 0.2799 & 9 & 19.2 & 16 & 0 & 0 & 0 & 0 & 0 & 0 \\
\hline 1 & $\begin{array}{c}\text { Chr2:2272 } \\
67027\end{array}$ & NA & COL4A3 & $\begin{array}{l}\text { STOP } \\
\text { GAINED }\end{array}$ & NA & 0 & 14.44 & 22.9 & 47 & 0 & 0 & 0 & 0 & 0 & 0 \\
\hline 1 & $\begin{array}{c}\text { Chr15:989 } \\
68575\end{array}$ & rs5814919 & $\begin{array}{c}\text { PGPEP1 } \\
L\end{array}$ & $\begin{array}{l}\text { FRAME } \\
\text { SHIFT }\end{array}$ & NA & 0.5109 & 0.09 & 0 & 6 & 0 & 0 & 0 & 0 & 0 & 0 \\
\hline 2 & $\begin{array}{c}\text { Chr2:2270 } \\
59568\end{array}$ & $\begin{array}{c}\text { rs } 1411270 \\
13\end{array}$ & COL4A4 & $\begin{array}{l}\text { FRAME } \\
\text { SHIFT }\end{array}$ & NA & 0 & 9 & 10.7 & 35 & 0 & 0 & 0 & 0 & 0 & 0 \\
\hline 2 & $\begin{array}{c}\text { Chr7:1007 } \\
73854\end{array}$ & NA & ZAN & $\begin{array}{l}\text { FRAME } \\
\text { SHIFT }\end{array}$ & NA & 0 & 0.005625 & 0 & 0.24 & 0 & 0 & 0 & 0 & 0 & 0 \\
\hline 2 & $\begin{array}{c}\text { Chr7:1007 } \\
87939\end{array}$ & $\begin{array}{c}\text { rs7236464 } \\
4\end{array}$ & ZAN & $\begin{array}{l}\text { FRAME } \\
\text { SHIFT }\end{array}$ & NA & 0.3732 & 0.005625 & 0 & 0.24 & 0 & 0 & 0 & 0 & 0 & 0 \\
\hline 2 & $\begin{array}{c}\text { Chr11:476 } \\
9643\end{array}$ & $\begin{array}{c}\text { rs } 3467292 \\
4\end{array}$ & OR51F1 & $\begin{array}{l}\text { FRAME } \\
\text { SHIFT }\end{array}$ & $\begin{array}{l}\text { Beni } \\
\text { gn }\end{array}$ & 0.2129 & 0 & 0 & 0.74 & 0 & 0 & 0 & 0 & 0 & 0 \\
\hline 2 & $\begin{array}{c}\text { Chr11:603 } \\
97879\end{array}$ & rs3217518 & MS4A14 & $\begin{array}{l}\text { FRAME } \\
\text { SHIFT }\end{array}$ & NA & 0.6394 & 0.25 & 0 & 10 & 0 & 0 & 0 & 0 & 0 & 0 \\
\hline 2 & $\begin{array}{c}\text { Chr17:407 } \\
01882\end{array}$ & $\begin{array}{c}\text { rs1130987 } \\
2\end{array}$ & KRT24 & $\begin{array}{l}\text { FRAME } \\
\text { SHIFT }\end{array}$ & NA & 0.4839 & 0.16 & 0 & 2 & 0 & 0 & 0 & 0 & 0 & 0 \\
\hline 2 & $\begin{array}{c}\text { Chr17:816 } \\
47906\end{array}$ & NA & $\begin{array}{c}\text { TSPAN1 } \\
0\end{array}$ & $\begin{array}{l}\text { FRAME } \\
\text { SHIFT + }\end{array}$ & NA & 0 & 0.04 & 0 & 6 & 0 & 0 & 0 & 0 & 0 & 0 \\
\hline
\end{tabular}


Washington_14_12_2019

\begin{tabular}{|c|c|c|c|c|c|c|c|c|c|c|c|c|c|c|c|}
\hline & & & & $\begin{array}{c}\text { STOP } \\
\text { GAINED }\end{array}$ & & & & & & & & & & & \\
\hline 2 & $\begin{array}{c}\text { Chr19:100 } \\
4897\end{array}$ & $\begin{array}{c}\text { rs } 1066658 \\
3\end{array}$ & GRIN3B & $\begin{array}{c}\text { FRAME } \\
\text { SHIFT }\end{array}$ & NA & 0.2448 & 0.09 & 0 & 10 & 0 & 0 & 0 & 0 & 0 & 0 \\
\hline 2 & $\begin{array}{c}\text { Chr19:523 } \\
83892\end{array}$ & $\begin{array}{c}\text { rs3447061 } \\
4\end{array}$ & ZNF880 & $\begin{array}{l}\text { FRAME } \\
\text { SHIFT }\end{array}$ & NA & 0.4718 & 4.84 & 6.2 & 13 & 0 & 0 & 0 & 0 & 0 & 0 \\
\hline
\end{tabular}

*expressed values are in Fragments per kilo base per million mapped reads (FPKM).

Supplementary Table S3: Coding variants found by NGS in COL4A4 and COL4A3 genes in chromosome 2.

\begin{tabular}{|c|c|c|c|c|c|c|c|c|c|c|c|c|c|c|c|}
\hline \multirow[t]{2}{*}{ Chr2:Position } & \multirow[t]{2}{*}{ SNP_ID } & \multirow[t]{2}{*}{ Mutation Type } & \multicolumn{5}{|c|}{ Proband Son Mother Father Proband } & \multicolumn{3}{|c|}{ Son MotherFather } & \multirow[t]{2}{*}{ Gene } & \multirow{2}{*}{$\begin{array}{c}\text { Amino acid } \\
\text { change }\end{array}$} & \multirow[t]{2}{*}{ ExAC } & \multirow{2}{*}{ ClinVar } & \multirow{2}{*}{$\begin{array}{c}\text { ClinVar Reported } \\
\text { as Alport } \\
\text { Condition? }\end{array}$} \\
\hline & & & (F1) & $(F 1)$ & $(F 1)$ & $(F 1)$ & $(F 2)$ & $(F 2)$ & $(F 2)$ & $(F 2)$ & & & & & \\
\hline 227007466 & rs2228557 & SYNONYMOUS & $\mathrm{G} \mid \mathrm{G}$ & $\mathrm{G} \mid \mathrm{G}$ & $\mathrm{G} \mid \mathrm{A}$ & $\mathrm{G} \mid \mathrm{G}$ & $\mathrm{G} \mid \mathrm{G}$ & $\mathrm{G} \mid \mathrm{A}$ & $\mathrm{G} \mid \mathrm{A}$ & $\mathrm{G} \mid \mathrm{A}$ & COL4A4 & p.Phe1644Phe & 0.4657 & Benign & Yes \\
\hline 227008279 & rs2228555 & SYNONYMOUS & $\mathrm{T} \mid \mathrm{T}$ & $\mathrm{T} \mid \mathrm{T}$ & $\mathrm{T} \mid \mathrm{C}$ & $\mathrm{T} \mid \mathrm{T}$ & $\mathrm{T} \mid \mathrm{T}$ & $\mathrm{T} \mid \mathrm{C}$ & $\mathrm{T} \mid \mathrm{C}$ & $\mathrm{T} \mid \mathrm{C}$ & COL4A4 & p.Val1516Val & 0.5602 & Benign & Yes \\
\hline 227022057 & rs3752895 & NON SYNONYMOUS & $\mathrm{A} \mid \mathrm{A}$ & $\mathrm{A} \mid \mathrm{A}$ & $\mathrm{A} \mid \mathrm{G}$ & $\mathrm{A} \mid \mathrm{A}$ & $\mathrm{A} \mid \mathrm{A}$ & $A \mid G$ & $\mathrm{~A} \mid \mathrm{G}$ & $\mathrm{A} \mid \mathrm{G}$ & COL4A4 & p.Ser1403Pro & 0.4763 & Benign & Yes \\
\hline 227027903 & rs2228556 & SYNONYMOUS & $\mathrm{C} \mid \mathrm{C}$ & $\mathrm{C} \mid \mathrm{C}$ & $\mathrm{C} \mid \mathrm{T}$ & $\mathrm{C} \mid \mathrm{C}$ & $\mathrm{C} \mid \mathrm{C}$ & $\mathrm{C} \mid \mathrm{T}$ & $\mathrm{C} \mid \mathrm{T}$ & $\mathrm{C} \mid \mathrm{T}$ & COL4A4 & p.Pro1360Pro & 0.4700 & Benign & Yes \\
\hline 227027942 & rs 16823077 & SYNONYMOUS & $\mathrm{T} \mid \mathrm{T}$ & $\mathrm{T} \mid \mathrm{T}$ & $\mathrm{T} \mid \mathrm{T}$ & $\mathrm{T} \mid \mathrm{T}$ & $\mathrm{T} \mid \mathrm{T}$ & $\mathrm{T} \mid \mathrm{C}$ & $\mathrm{T} \mid \mathrm{T}$ & $\mathrm{T} \mid \mathrm{C}$ & COL4A4 & p.Leu1347Leu & 0.0070 & Benign & Yes \\
\hline 227032170 & rs2229812 & SYNONYMOUS & $\mathrm{C} \mid \mathrm{C}$ & $\mathrm{C} \mid \mathrm{C}$ & $\mathrm{C} \mid \mathrm{T}$ & $\mathrm{C} \mid \mathrm{C}$ & $\mathrm{C} \mid \mathrm{C}$ & $\mathrm{C} \mid \mathrm{T}$ & $\mathrm{ClT}$ & $\mathrm{C} \mid \mathrm{T}$ & COL4A4 & p.Lys1228Lys & 0.4716 & Benign & Yes \\
\hline 227032260 & rs 10203363 & SYNONYMOUS & $\mathrm{C} \mid \mathrm{C}$ & $\mathrm{C} \mid \mathrm{C}$ & $\mathrm{C} \mid \mathrm{T}$ & $\mathrm{C} \mid \mathrm{C}$ & $\mathrm{C} \mid \mathrm{C}$ & $\mathrm{C} \mid \mathrm{T}$ & $\mathrm{C} \mid \mathrm{T}$ & $\mathrm{C} \mid \mathrm{T}$ & COL4A4 & p.Gly1198Gly & 0.4746 & Benign & Yes \\
\hline
\end{tabular}




\begin{tabular}{|c|c|c|c|c|c|c|c|c|c|c|c|c|c|c|}
\hline 227051116 & rs1800517 NON_SYNONYMOUS & $\mathrm{G} \mid \mathrm{G}$ & $\mathrm{G} \mid \mathrm{G}$ & $\mathrm{G} \mid \mathrm{A}$ & $\mathrm{G} \mid \mathrm{G}$ & $\mathrm{G} \mid \mathrm{G}$ & $\mathrm{G} \mid \mathrm{A}$ & $\mathrm{G} \mid \mathrm{A}$ & $\mathrm{G} \mid \mathrm{A}$ & COL4A4 & p.Pro1004Leu & 0.5205 & Benign & Yes \\
\hline 227052374 & rs80243096NON_SYNONYMOUS & $\mathrm{T} \mid \mathrm{T}$ & $\mathrm{T} \mid \mathrm{T}$ & $\mathrm{T} \mid \mathrm{T}$ & $\mathrm{T} \mid \mathrm{T}$ & $\mathrm{C} \mid \mathrm{C}$ & $\mathrm{C} \mid \mathrm{T}$ & $\mathrm{C} \mid \mathrm{T}$ & $\mathrm{C} \mid \mathrm{T}$ & COL4A4 & p.lle967Val & 0.0073 & Benign & Yes \\
\hline 227059568 & $\begin{array}{c}\text { rs } 14112701 \\
3\end{array}$ & $\mathrm{~A} \mid \mathrm{A}$ & $\mathrm{A} \mid \mathrm{A}$ & $\mathrm{A} \mid \mathrm{A}$ & $\mathrm{A} \mid \mathrm{A}$ & $A G \mid A G$ & $A G \mid A$ & $A G \mid A$ & $A G \mid A$ & COL4A4 & p.Val741fs & .0 .0000 & $\begin{array}{c}\text { Not } \\
\text { Reported }\end{array}$ & No \\
\hline 227089883 & rs2229814 NON SYNONYMOUS & $\mathrm{G} \mid \mathrm{G}$ & $\mathrm{G} \mid \mathrm{G}$ & $\mathrm{G} \mid \mathrm{A}$ & $\mathrm{G} \mid \mathrm{G}$ & $\mathrm{A} \mid \mathrm{A}$ & $\mathrm{A} \mid \mathrm{A}$ & $\mathrm{A} \mid \mathrm{A}$ & $\mathrm{A} \mid \mathrm{A}$ & COL4A4 & p.Pro482Ser & 0.5344 & Benign & Yes \\
\hline 227147467 & rs16823264 NON SYNONYMOUS & $\mathrm{A} \mid \mathrm{A}$ & $\mathrm{A} \mid \mathrm{A}$ & $\mathrm{A} \mid \mathrm{A}$ & $\mathrm{A} \mid \mathrm{A}$ & $\mathrm{A} \mid \mathrm{A}$ & $A \mid G$ & $A \mid G$ & $A \mid G$ & COL4A4 & p.Ile6Thr & 0.0285 & Benign & Yes \\
\hline 227238007 & rs13424243 NON SYNONYMOUS & $\mathrm{G} \mid \mathrm{G}$ & $\mathrm{G} \mid \mathrm{C}$ & $\mathrm{G} \mid \mathrm{C}$ & $\mathrm{G} \mid \mathrm{C}$ & $\mathrm{C} \mid \mathrm{C}$ & $\mathrm{C} \mid \mathrm{C}$ & $\mathrm{C} \mid \mathrm{G}$ & $\mathrm{C} \mid \mathrm{C}$ & COL4A3 & p.Gly43Arg & 0.2884 & Benign & Yes \\
\hline 227246719 & rs10178458 NON SYNONYMOUS & $\mathrm{C} \mid \mathrm{C}$ & $\mathrm{C} \mid \mathrm{C}$ & $\mathrm{C} \mid \mathrm{C}$ & $\mathrm{C} \mid \mathrm{C}$ & $\mathrm{C} \mid \mathrm{C}$ & $\mathrm{C} \mid \mathrm{T}$ & $\mathrm{C} \mid \mathrm{C}$ & $\mathrm{C} \mid \mathrm{T}$ & COL4A3 & p.Leu141Pro & 0.8302 & Benign & Yes \\
\hline 227248459 & rs6436669 NON SYNONYMOUS & $\mathrm{G} \mid \mathrm{G}$ & $\mathrm{G} \mid \mathrm{G}$ & $\mathrm{G} \mid \mathrm{G}$ & $\mathrm{G} \mid \mathrm{G}$ & $\mathrm{G} \mid \mathrm{G}$ & $\mathrm{G} \mid \mathrm{A}$ & $\mathrm{G} \mid \mathrm{G}$ & $\mathrm{G} \mid \mathrm{A}$ & COL4A3 & p.Glu162Gly & 0.8304 & Benign & Yes \\
\hline 227263824 & SYNONYMOUS & $\mathrm{T} \mid \mathrm{T}$ & $\mathrm{T} \mid \mathrm{T}$ & $\mathrm{T} \mid \mathrm{T}$ & $\mathrm{T} \mid \mathrm{T}$ & $\mathrm{T} \mid \mathrm{T}$ & $\mathrm{T} \mid \mathrm{T}$ & $\mathrm{T} \mid \mathrm{C}$ & $\mathrm{T} \mid \mathrm{T}$ & COL4A3 & p.Leu399Leu & 0.7667 & Benign & Yes \\
\hline 227266453 & rs11677877 NON SYNONYMOUS & $\mathrm{A} \mid \mathrm{A}$ & $\mathrm{A} \mid \mathrm{A}$ & $\mathrm{A} \mid \mathrm{A}$ & $\mathrm{A} \mid \mathrm{A}$ & $\mathrm{A} \mid \mathrm{A}$ & $A \mid G$ & $\mathrm{~A} \mid \mathrm{A}$ & $A \mid G$ & COL4A3 & p.His451Arg & 0.0944 & Benign & Yes \\
\hline 227267027 & STOP_GAINED & $\mathrm{A} \mid \mathrm{A}$ & $\mathrm{A} \mid \mathrm{T}$ & $\mathrm{A} \mid \mathrm{T}$ & $\mathrm{A} \mid \mathrm{T}$ & $\mathrm{T} \mid \mathrm{T}$ & $\mathrm{T} \mid \mathrm{T}$ & $\mathrm{T} \mid \mathrm{T}$ & $\mathrm{T} \mid \mathrm{T}$ & COL4A3 & p.Tyr481* & 0.0000 & $\begin{array}{c}\text { Not } \\
\text { Reported }\end{array}$ & No \\
\hline 227267036 & SYNONYMOUS & $\mathrm{G} \mid \mathrm{G}$ & $\mathrm{G} \mid \mathrm{G}$ & $\mathrm{G} \mid \mathrm{G}$ & $\mathrm{G} \mid \mathrm{G}$ & $\mathrm{G} \mid \mathrm{G}$ & $\mathrm{G} \mid \mathrm{A}$ & $\mathrm{G} \mid \mathrm{G}$ & $\mathrm{G} \mid \mathrm{A}$ & COL4A3 & p.Gly484Gly & 0.0923 & Benign & Yes \\
\hline 227270915 & rs28381984 NON SYNONYMOUS & $\mathrm{T} \mid \mathrm{T}$ & $\mathrm{T} \mid \mathrm{T}$ & $\mathrm{T} \mid \mathrm{T}$ & $\mathrm{T} \mid \mathrm{T}$ & $\mathrm{T} \mid \mathrm{T}$ & $\mathrm{T} \mid \mathrm{C}$ & $\mathrm{T} \mid \mathrm{C}$ & $\mathrm{T} \mid \mathrm{C}$ & COL4A3 & p.Pro574Leu & 0.4694 & Benign & Yes \\
\hline 227283825 & SYNONYMOUS & $\mathrm{C} \mid \mathrm{C}$ & $\mathrm{C} \mid \mathrm{C}$ & $\mathrm{C} \mid \mathrm{C}$ & $\mathrm{C} \mid \mathrm{C}$ & $\mathrm{C} \mid \mathrm{C}$ & $\mathrm{C} \mid \mathrm{T}$ & $\mathrm{C} \mid \mathrm{C}$ & $\mathrm{C} \mid \mathrm{T}$ & COL4A3 & p.Pro905Pro & 0.0051 & Benign & Yes \\
\hline 227298737 & rs57611801 NON SYNONYMOUS & $\mathrm{C} \mid \mathrm{C}$ & $\mathrm{C} \mid \mathrm{C}$ & $\mathrm{C} \mid \mathrm{C}$ & $\mathrm{C} \mid \mathrm{C}$ & $\mathrm{C} \mid \mathrm{C}$ & $\mathrm{C} \mid \mathrm{C}$ & $\mathrm{C} \mid \mathrm{A}$ & $\mathrm{C} \mid \mathrm{C}$ & COL4A3 & p.Asp1269Glu & 0.0441 & Benign & Yes \\
\hline
\end{tabular}


Figure 2. COL4A4 and COL4A3 alleles co-segregating. Figure indicates the variants of chromosome 2 for COL4A4 and COL4A3 of all individuals in families, in homozygosity (non-synonymous variant in red, homozygous non-synonymous variant in yellow). The probands are in black. Black * defines a stop codon gain in proband of Family 1 and a frame-shift in proband of Family 2. 


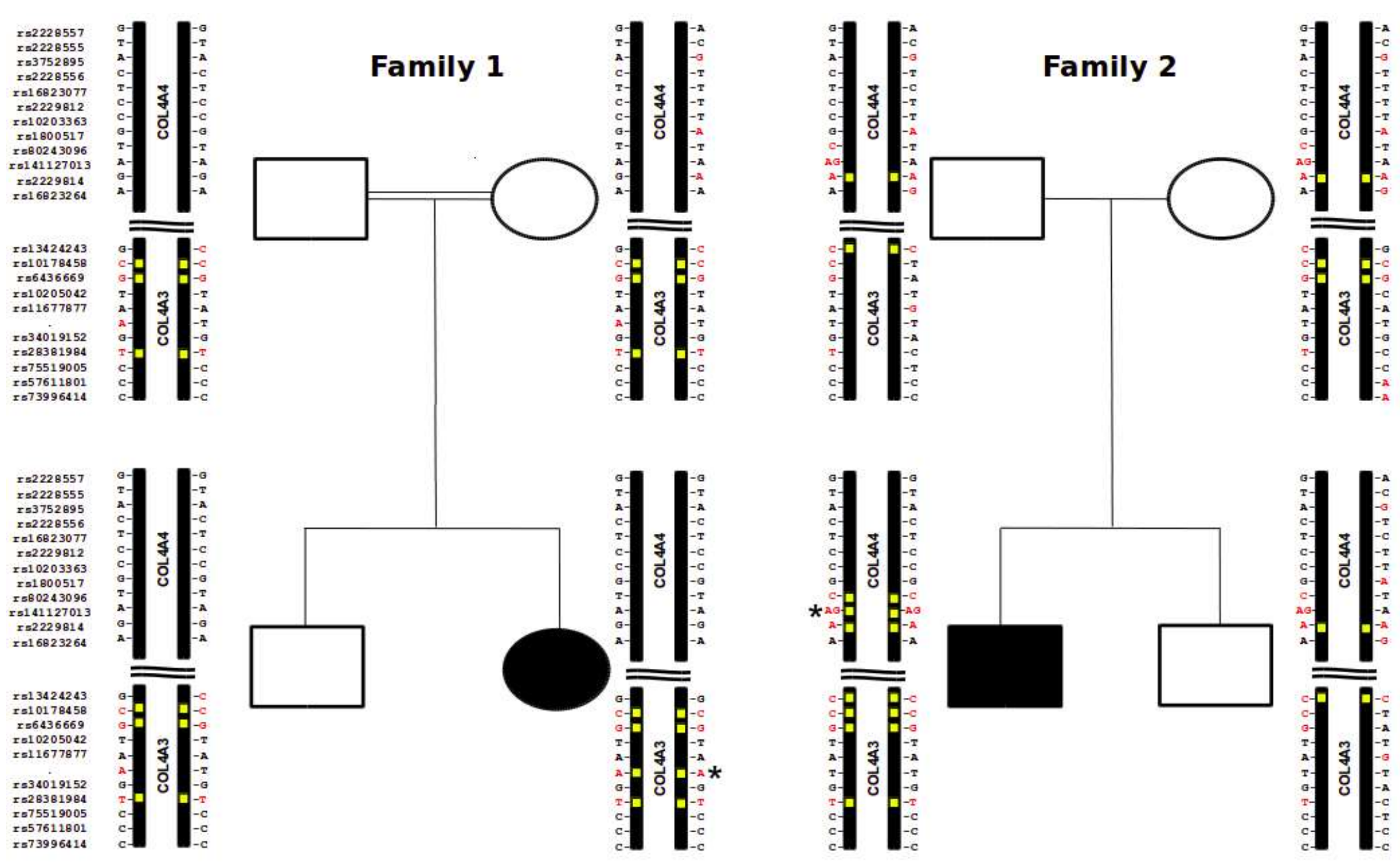


Washington_14_12_2019

Table 1: Normalized mean coverage by samples in $\mathrm{ROH}$ and remaining regions for complete chromosome 2 extension

\begin{tabular}{cccc}
\hline Sample & $\begin{array}{c}\text { Total Mapped } \\
\text { reads to chr2 }\end{array}$ & $\begin{array}{c}\text { Normalized } \\
\text { mean coverage } \\
\text { in homozygous } \\
\text { region }\end{array}$ & $\begin{array}{c}\text { Normalized mean } \\
\text { coverage in } \\
\text { remaing regions }\end{array}$ \\
\hline Father (F1) & $11,361,323$ & 191.45 & 195.62 \\
\hline Mother (F1) & $12,778,526$ & 186.90 & 190.10 \\
\hline Son (F1) & $14,695,917$ & 183.38 & 184.14 \\
\hline Proband (F1) & $10,429,522$ & 189.51 & 191.46 \\
\hline Father (F2) & $15,160,228$ & 192.15 & 191.13 \\
\hline Mother (F2) & $13,382,947$ & 198.62 & 192.09 \\
\hline Son (F2) & $13,375,114$ & 198.19 & 194.00 \\
\hline Proband (F2) & $11,124,247$ & 200.07 & 194.61 \\
\hline
\end{tabular}


Figure 3. Differences between homozygous and heterozygous signals in complete chromosome 2 extension. A) Family 1, B) Family 2. Black arrow shows where homozygosity region begins in both probands (dark blue line). Red and green * define COL4A4 and COL4A3 genes respectively.
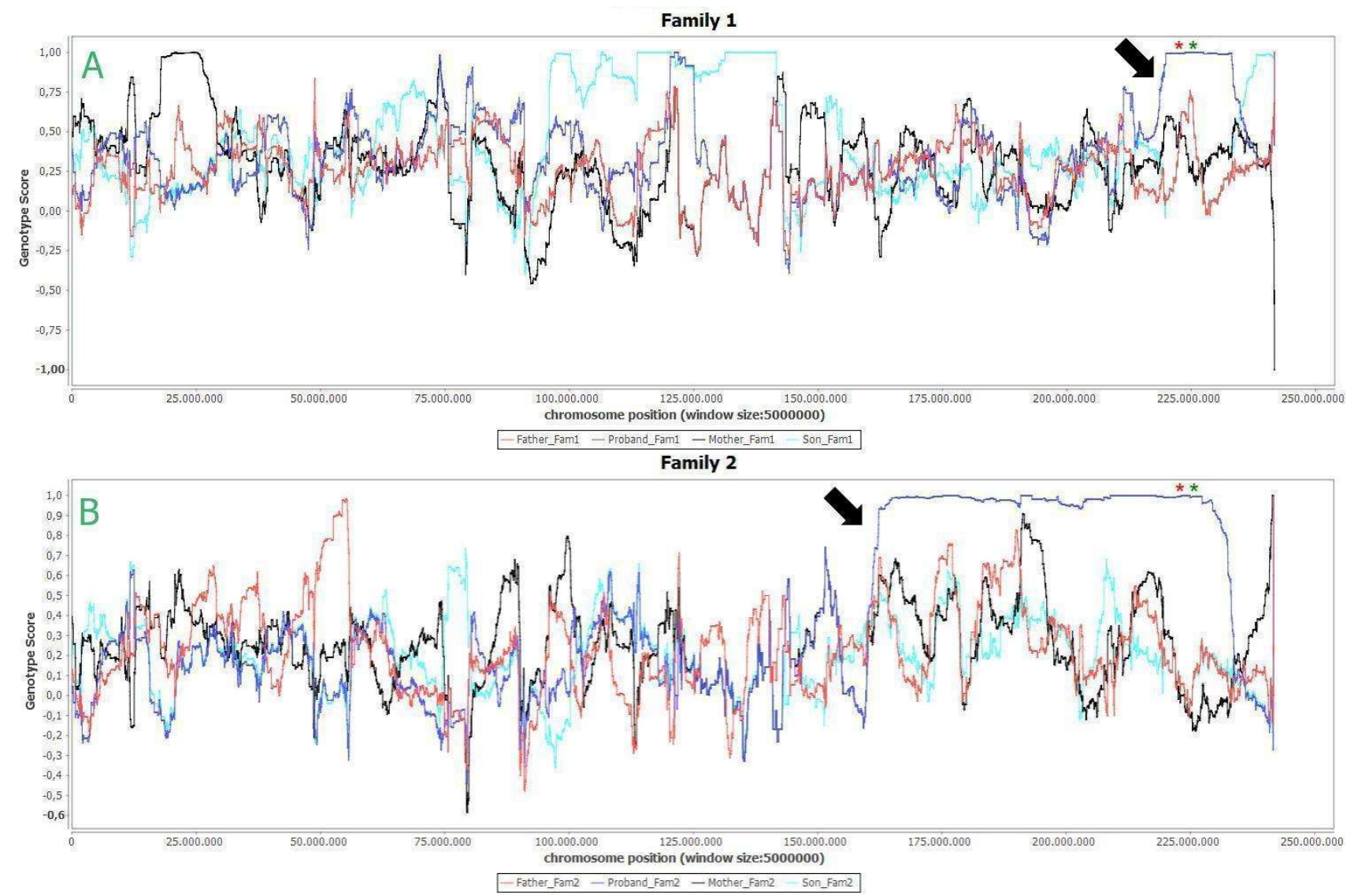
Washington_14_12_2019

Table 2. Number and total length of ROHs of the Family 1.

\begin{tabular}{|c|c|c|c|}
\hline Sample & $\begin{array}{c}\text { Number of ROHs } \\
\text { (cut-off 1.5 Mb) }\end{array}$ & $\begin{array}{c}\text { Total ROH length } \\
\text { (cut-off 1.5 Mb) }\end{array}$ & Homozygous ratio \\
\hline Father & 44 & $123,049,309$ & 1.05 \\
\hline Mother & 55 & $251,514,461$ & 2.15 \\
\hline Son & 72 & $413,645,034$ & 3.53 \\
\hline Proband & 47 & $237,564,469$ & 2.03 \\
\hline
\end{tabular}

Table 3. Number and total length of ROHs of the Family 2.

\begin{tabular}{|c|c|c|c|}
\hline Sample & $\begin{array}{c}\text { Number of ROHs } \\
\text { (cut-off 1.5 Mb) }\end{array}$ & $\begin{array}{c}\text { Total ROH length } \\
\text { (cut-off 1.5 Mb) }\end{array}$ & Homozygous ratio \\
\hline Father & 31 & $82,570,772$ & 0.70 \\
\hline Mother & 29 & $65,961,650$ & 0.56 \\
\hline Son & 60 & $368,429,799$ & 3.15 \\
\hline Proband & 51 & $244,287,314$ & 2.09 \\
\hline
\end{tabular}




\begin{tabular}{|c|cc|}
\hline \multicolumn{2}{|c|}{ Supplementary Table S4: CEU populations of the 1000 Genomes Project. } \\
\hline CEU sample & \#ROH regions (cut-off 1.5 Mb) & Total ROH length (cut-off 1.5 Mb) \\
\hline NA07347 & 39 & $106,376,199$ \\
\hline NA11831 & 48 & 136,881072 \\
\hline NA11830 & 38 & 101,034986 \\
\hline NA10851 & 47 & 129,703972 \\
\hline NA11832 & 44 & 107,741456 \\
\hline NA07357 & 55 & 152,663835 \\
\hline NA11843 & 55 & 149,934599 \\
\hline NA06989 & 48 & $113,842,564$ \\
\hline NA07056 & 53 & 165109,126 \\
\hline NA06984 & 40 & $122,85,835$ \\
\hline NA07037 & 33 & $81,158,923$ \\
\hline NA06985 & 48 & $122,109,441$ \\
\hline NA07051 & 40 & $91,727,641$ \\
\hline NA07048 & 33 & $93,706,363$ \\
\hline NA11840 & 40 & $98,139,215$ \\
\hline NA11829 & 42 & $129,474,178$ \\
\hline NA10847 & 36 & $99,052,682$ \\
\hline & & \\
\hline
\end{tabular}


Washington_14_12_2019

\begin{tabular}{|c|c|c|}
\hline NA07000 & 48 & $134,365,628$ \\
\hline NA06986 & 40 & $114,937,185$ \\
\hline NA06994 & 33 & $86,687,035$ \\
\hline
\end{tabular}

